\title{
$\operatorname{Cox} F .970909--2$
}

\section{POINT DEFECT CONCENTRATIONS AND SOLID SOLUTION HARDENING IN NIAI WITH Fe ADDITIONS}

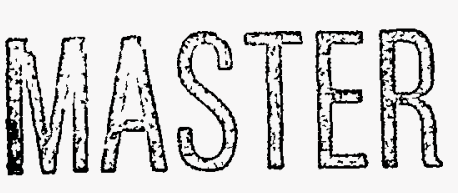

\section{M. Pike, C. T. Liu*, and Y.A. Chang}

Department of Materials Science and Engineering

University of Wisconsin, Madison, WI 53706-1595

* Metals and Ceramics Division, Oak Ridge National Laboratory Oak Ridge, TN 37831-6115

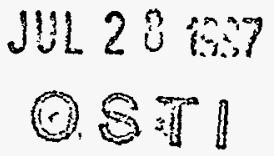

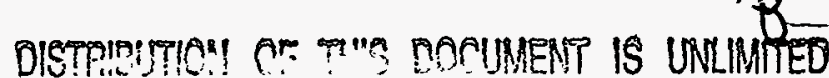

\section{Abstract}

The solid solution hardening behavior exhibited when $\mathrm{Fe}$ is added to NiAl is investigated. This is an interesting problem to consider since the ternary Fe additions may choose to occupy either the $\mathrm{Ni}$ or the $\mathrm{Al}$ sublattice, affecting the hardness at differing rates. Moreover, the addition of Fe may affect the concentrations of other point defects such as vacancies and $\mathrm{Ni}$ anti-sites. As a result, unusual effects ranging from rapid hardening to solid solution softening are observed. Alloys with varying amounts of $\mathrm{Fe}$ were prepared in Ni-rich (40 at. \% Al) and stoichiometric (50 at. \% Al) compositions. Vacancy concentrations were measured using lattice parameter and density measurements. The site occupancy of $\mathrm{Fe}$ was determined using ALCHEMI. Using these two techniques the site occupancies of all species could be uniquely determined. Significant differences in the defect concentrations as well as the hardening behavior were encountered between the $\mathrm{Ni}$-rich and stoichiometric regimes.

\subsection{Introduction}

Point defects, such as vacancies and anti-site defects, are known to strongly affect the properties of intermetallic compounds with the B2 crystal structure. For example, the off-stoichiometric hardening observed in $\mathrm{NiAl}$ has been attributed to the presence of constitutional defects (1). Thermally generated defects have also been reported to strongly affect the mechanical properties of such B2 compounds as FeAl, CoAl, and FeCo (2-4). In a similar manner, the addition of ternary or higher order alloy additions can strongly affect the mechanical and physical properties of $\mathrm{B} 2$ compounds, e.g. NiAl $(5,6)$. The addition of a ternary element to an ordered binary compound can drastically affect the concentrations of point defects. These defects are often directly responsible for the observed property changes. It is clear that any investigation of the effects of ternary alloying in this class of materials would benefit from a knowledge of the point defect concentration which result from this alloying. It will be the purpose of this investigation to examine the effect of substitutional ternary alloy additions on both the point defect structure and the resultant solid solution hardening behavior of an ordered B2 compound. The system chosen to investigate is $\mathrm{NiAl}$ with ternary $\mathrm{Fe}$ additions. This system is of interest since it has been reported that $\mathrm{Fe}$ additions affect the room temperature ductility (7) and high temperature creep properties (8) of NiAl.

\subsection{Experimental}

The experiments discussed in this paper are part of a larger study which will be presented elsewhere. For this reason only a brief review of the experimental details will be given here. Twelve alloys were prepared from high purity starting elements by arc meiting. Alloys with up to 12 at. $\% \mathrm{Fe}$ were made in two stoichiometric: Ni-rich (40 at. \% Al) and stoichiometric (50 at. \% Ai). The compositions of the eight alloys are given in Table I. The as-cast alloys were then subjected to homogenizing heat

\section{DISCLAIMER}

This report was prepared as an account of work sponsored by an agency of the United States Government. Neither the United States Government nor any agency thereof, nor any of their employees, makes any warranty, express or implied, or assumes any legal liability or responsibility for the accuracy, completeness, or usefulness of any information, apparatus, product, or process disclosed, or represents that its use would not infringe privately owned rights. Reference herein to any specific commercial product, process, or service by trade name, trademark, manufacturer, or otherwise does not necessarily constitute or imply its endorsement, recommendation, or favoring by the United States Government or any agency thereof. The views and opinions of authors expressed herein do not necessarily state or reflect those of the United States Government or any agency thereof. 


\section{DISCLAMIER}

Portions of this document may be illegible in electronic image products. Images are produced from the best available original document. 
Table I. The Compositions and Properties of the Alloys in this Study, as Quenched from 700 and $1000^{\circ} \mathrm{C}$

\begin{tabular}{|c|c|c|c|c|c|c|c|c|c|c|}
\hline \multirow[t]{2}{*}{$\% \mathrm{Ni}$} & \multirow[t]{2}{*}{$\% \mathrm{Fe}$} & \multirow[t]{2}{*}{$\% \mathrm{Al}$} & \multicolumn{2}{|c|}{$\begin{array}{l}\text { Lattice Parameter } \\
\qquad(\AA)\end{array}$} & \multicolumn{2}{|c|}{$\begin{array}{l}\text { Bulk Density } \\
\left(\mathrm{g} / \mathrm{cm}^{3}\right)\end{array}$} & \multicolumn{2}{|c|}{$\begin{array}{c}\text { Vacancy } \\
\text { Concentration }\end{array}$} & \multicolumn{2}{|c|}{$\begin{array}{l}\text { Hardness } \\
\text { (GPa) }\end{array}$} \\
\hline & & & $00^{\circ} \mathrm{C}$ & $1000^{\circ} \mathrm{C}$ & $700^{\circ} \mathrm{C}$ & $1000^{\circ} \mathrm{C}$ & $700^{\circ} \mathrm{C}$ & $1000^{\circ} \mathrm{C}$ & $700^{\circ} \mathrm{C}$ & $1000^{\circ} \mathrm{C}$ \\
\hline 60 & 0 & 40 & 2.8674 & 2.8663 & 6.494 & 6.476 & -0.002 & 0.002 & 4.17 & 4.14 \\
\hline 57.6 & 2.4 & 40 & 2.8710 & 2.8707 & 6.439 & 6.437 & 0.001 & 0.002 & 3.78 & 3.90 \\
\hline 54 & 6 & 40 & 2.8770 & 2.8765 & 6.385 & 6.377 & 0.001 & 0.003 & 3.37 & 3.53 \\
\hline 48 & 12 & 40 & $\therefore .8836$ & 2.8832 & 6.319 & 6.314 & 0.001 & 0.002 & 2.98 & 2.98 \\
\hline 50 & 0 & 50 & 28876 & 28881 & 5901 & 5886 & 0,001 & 0003 & 250 & 255 \\
\hline 48 & 2 & 50 & 2.8881 & 2.8873 & 5.883 & 5.878 & 0.003 & 0.004 & 2.64 & 2.69 \\
\hline 45 & 5 & 50 & 2.8878 & 2.8868 & $\cdots$ & 5.842 & $\ldots$ & 0.009 & 3.06 & 3.13 \\
\hline 40 & 10 & 50 & 2.8878 & 2.8861 & 5.813 & 5.800 & 0.010 & 0.013 & 3.66 & 3.77 \\
\hline
\end{tabular}

treatments. Fine powders were prepared from these ingots and given a heat treatment (in vacuum) of $5 \mathrm{~h} / 1000^{\circ} \mathrm{C}+$ water quench (WQ). The lattice parameters of these powders were measured using $\mathrm{x}$-ray diffraction. The remaining portion of the ingots were given a heat treatment of $5 \mathrm{~h} / 1000^{\circ} \mathrm{C}+\mathrm{WQ}$. Sections of the ingots (approximate dimensions: $10 \times 10 \times 5$ $\mathrm{mm}$ ) were then taken for hardness measurements. The other sections of the ingots were crushed into a coarse powder for derisity measurements. The density measurements were made using the hydrostatic method. After the lartice parameter. density and hardness measurements, the samples were given a subsequent anneal for $3 \mathrm{~d} / 700^{\circ} \mathrm{C}+W Q$. The measurements were then repeated. From the lattice parameter and density data. the vacancy concentration of the alloys could be calculated. One discussion of this type of calculation can be found in the review by Chang and Neumann (9).

Selected compositions from above were chosen for analysis with the TEM technique. ALCHEMI. Rods were prepared by arc melting followed by drop casting. These ingots were given homogenizing heat treatments followed by a treatment of $3 \mathrm{~d} / 700^{\circ} \mathrm{C}+$ WQ. TEM samples were prepared from the quenched rods. The details of the ALCHEMI technique will not be presented here, but follow the methods used by Anderson et. al. (10).

\subsection{Results and Discussion}

\subsection{Point Defect Hardening in Binary B2 Compounds}

Before attempting to discuss solid solution hardening in a ternary B2 compound it is helpful to review the defect structure and point defect hardening in binary B2 compounds, especially for the NiAl system itself. It has been shown that the defect structure of NiAl can be approximated with the triple defect model $(9,11)$. This model is based on the assumption that the majority of defects present are either vacancies on the $\mathrm{Ni}$ sublattice or $\mathrm{Ni}$ atoms on the $\mathrm{Al}$ sublattice (Ni anti-sites). Defects can be present either as constitutional or thermal defects. Constitutional defects consist of $\mathrm{Ni}$ anti-sites at Ni-rich compositions and vacancies at Al-rich compositions. Thermal defects consist of vacancies and $\mathrm{Ni}$ anti-sites occurring in a two to one ratio. This ratio maintains the site balance of the crystal. The concentrations of vacancies as well as $\mathrm{Ni}$ anti-site defects in NiAl as a function of composition are shown in Fig. I. The lines in this figure are values estimated from the thermodynamic model of Chang and Neumann (9). The data points are experimentally measured vacancy concentrations taken from Pike et. al. (4). Good agreement is seen between the model and the experimental values. Off-stoichiometric hardening occurs at both Ni-rich and Al-rich compositions. This hardening has been attributed to Ni anti-sites and vacancies. respectively (1). A recent study by Pike et. al. examined the point defect hardening in several B2 compounds including NiAl. It was found that the hardness could often be correlated to the square root of the hardening defect concentration. following the relationship derived for yield stresses in one solid solution hardening (SSH) theory (12). In Fig. 2 the offstoichiometric hardening in NiAl is plotted vs. the square root of the hardening defect concentration for both $\mathrm{Ni}$-rich and Al-rich compositions. The hardening rate of vacancies is seen to be significantly greater than that of the Ni anti-sites. For all of the B2 compounds considered by Pike et. al.. the hardening rates $(\gamma=$ $d H / d \sqrt{c}$ where $H$ is hardness and $c$ is the hardening defect concentration) of defects fell into two distinct groups. Those of anti-site defects fell in the range $G / 9$ to $G / 75$ and could be linearly related to the term $1 / a / d a / d c \mid$ which is a measure of the elastic dilation of the lattice (where $G$ is the shear modulus and $a$ is the lattice parameter). This suggests that the elastic "size effect" is at least partially responsible for the hardening caused by anti-site defects. The hardening rates of vacancies fell in the range $G / 3.1$ to G/4.1. Thus, vacancies are considerably more effective hardeners than are anti-site defects. A correlation between the hardening rates of vacancies and the lattice dilation was not found. The hardening rate of vacancies may be affected by such factors as clustering or association with impurities.

\subsection{Point Defect Concentrations in Fe-doped NiAl}

To understand the SSH which results from ternary alloying Fe to NiAl, it is important to first develop an understanding of the point defect concentrations which arise as a result of this alloying. Firstly, the $\mathrm{Fe}$ additions may occupy either the $\mathrm{Ni}$ or the Al sublattice (or both), affecting the hardness in significantly different fashions. Secondly, the addition of $\mathrm{Fe}$ may affect other point defect concentrations such as vacancies or $\mathrm{Ni}$ anti-site defects. For this reason the first step in our analysis will be to determine the defect concentrations which result from ternary alloying $\mathrm{Fe}$ to $\mathrm{NiAl}$.

In a triple defect compound such as NiAl, it is assumed that the Al anti-site $\left(A I^{N i}\right)$ and Al-site vacancy $\left(\square^{A l}\right)$ concentrations are negligible (we have introduced the notation $A^{b}$ to indicate the 


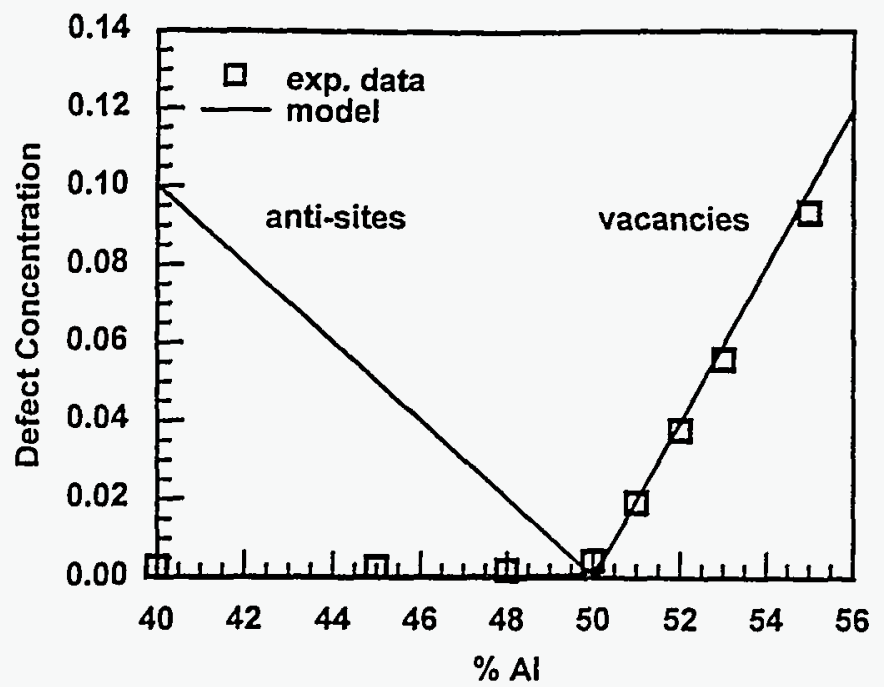

Figure 1: The vacancy and $\mathrm{Ni}$ anti-site concentrations in NiAl at $1000^{\circ} \mathrm{C}$ as calculated from the thermodynamic model along with experimentally determined vacancy concentrations of samples quenched from $1000^{\circ} \mathrm{C}(4)$.

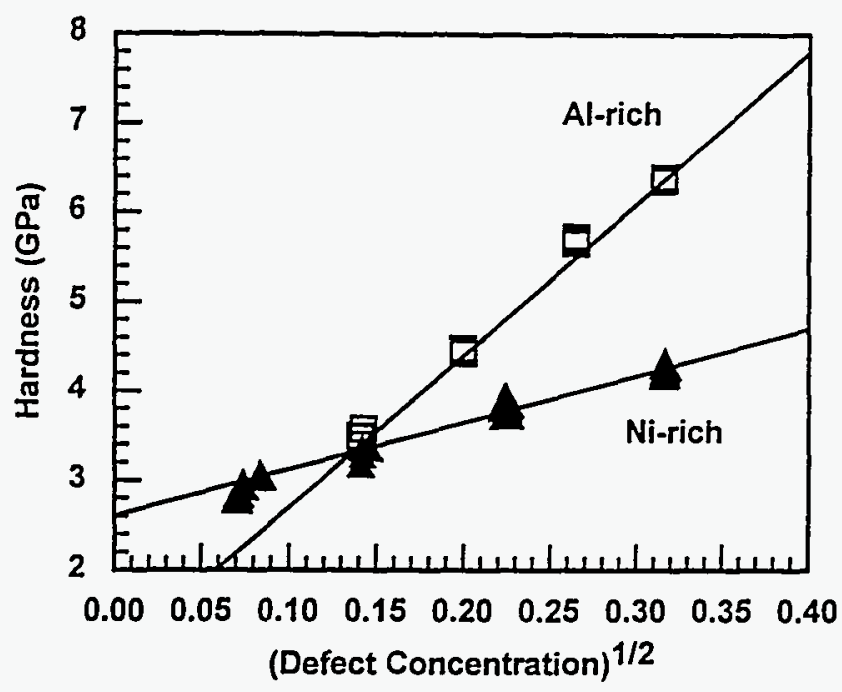

Figure 2: The hardness of $\mathrm{Ni}$-rich and Al-rich $\mathrm{NiAl}$ vs. the square root of the $\mathrm{Ni}$ anti-site and vacancy concentrations, respectively (4).

species $A$ located on the $b$ sublattice; the symbol $\square$ represents a vacancy). Therefore, there are six site occupancies which must be determined to fully characterize the point defect concentration of the crystal. These are the concentrations of $\mathrm{Ni}^{\mathrm{Ni}}, \mathrm{Fe}^{\mathrm{Ni}}, \square^{\mathrm{Ni}}, \mathrm{Ni}^{\mathrm{Al}}, \mathrm{Fe}^{\mathrm{Al}}$, and $\mathrm{Al}^{\mathrm{Al}}$. Through mass and site balances the number of unknowns is reduced to two. Thus, there are two experimental variables which must be determined for any given composition and heat treatment in order to determine all point defect concentrations. The first variable we will measure is the vacancy concentration which can be determined by combining lattice parameter and bulk density measurements. This has been done for a number of binary B2 compounds $(4,9)$. A second experimental variable can be determined using the TEM technique ALCHEMI. Many experimental difficulties which plagued the accuracy of early work using this technique have recently been overcome. Using this improved technique Anderson (13) was able to determine the site preference of several ternary additions to the FeAl system. In the present study ALCHEMI was used to determine the $\mathrm{Fe}^{\mathrm{Ni}} / \mathrm{Ni}^{\mathrm{Ni}}$ ratio of several alloys. This information, combined with the vacancy concentration measurements was enough to fully determine the site occupancies resulting from $\mathrm{Fe}$ additions to $\mathrm{NiAl}$.

3.2.1 Fe added to Ni-rich NiAl. First we will consider the case where $\mathrm{Fe}$ is added to replace $\mathrm{Ni}$ in $\mathrm{Ni}-40 \mathrm{Al}$. Alloys were made from 0 to 12 at. $\% \mathrm{Fe}$, i.e. $\mathrm{Ni}_{60-\mathrm{x}} \mathrm{Fe}_{\mathrm{x}} \mathrm{Al}_{40}$ where $\mathrm{x}$ varies from 0 to 12. The lattice parameters of these alloys as quenched from $1000^{\circ} \mathrm{C}$ are shown in Fig. 3. The lattice parameter is seen to increase with increasing $\mathrm{Fe}$ concentration. The bulk densities of these alloys are listed in Table $\mathrm{I}$. The vacancy concentrations as quenched from $1000^{\circ} \mathrm{C}$, as calculated from the lattice parameter and bulk density, are shown in Fig. 4. Here the vacancy concentration is defined as the number of vacancies per the total number of atoms in the crystal. It can be seen that the vacancy concentration is around $0.002(0.2 \%)$ for all compositions. This is a relatively small value and approaches the threshold of detection. The vacancy concentration of these alloys as quenched from $700^{\circ} \mathrm{C}$ was also found to be very small. The $\mathrm{Fe}^{\mathrm{Ni}} / \mathrm{Ni}^{\mathrm{Ni}}$ ratio of samples quenched from $700^{\circ} \mathrm{C}$ was determined using ALCHEMI. This data combined with the vacancy concentration data. provided the information needed to determine the concentrations of $\mathrm{Ni}$ and $\mathrm{Fe}$ on the $\mathrm{Al}$ sublattice (which we will refer to as $\mathrm{Ni}$ and $\mathrm{Fe}$ anti-site defects, respectively). These are shown in Fig. 5. From this figure it is clear that as $\mathrm{Fe}$ is added to $\mathrm{Ni}-40 \mathrm{Al}$. Fe anti-site defects begin to replace the $\mathrm{Ni}$ anti-site defects. This trend continues until around 10 at. $\% \mathrm{Fe}$ where the anti-site concentrations begin to level off. At this point $\mathrm{Fe}$ begins to occupy the $\mathrm{Ni}$ sublattice in significant numbers. The $\mathrm{Fe}^{\mathrm{Ni}}$ concentration is also shown in Fig. 5 and is significantly lower than the $\mathrm{Fe}$ anti-site $\left(\mathrm{Fe}^{\mathrm{Al}}\right.$ ) concentration for all of the alloys. These results clearly indicate that $\mathrm{Fe}$ atoms preferentially occupy the Al sublattice in $\mathrm{Ni}$-rich $\mathrm{NiAl}$. The above results are in qualitative agreement with predictions based on thermodynamic considerations (14).

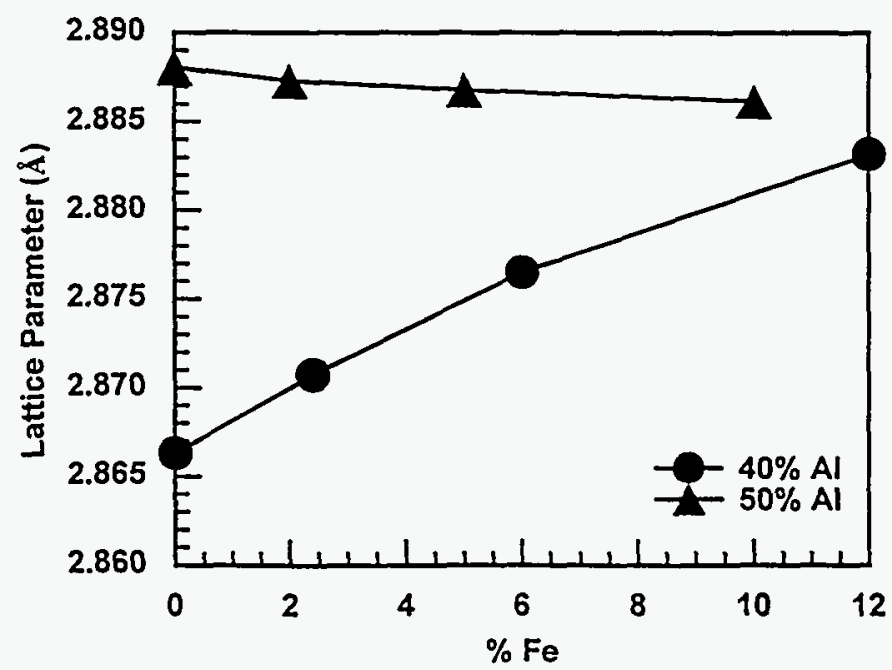

Figure 3: The lattice parameter vs. Fe concentration. 


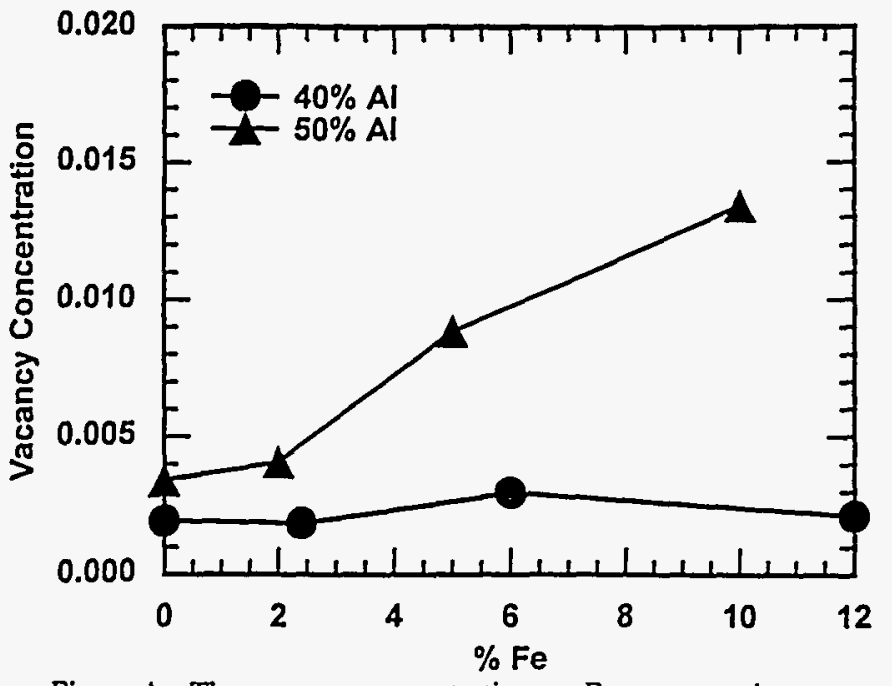

Figure 4: The vacancy concentration vs. Fe concentration.

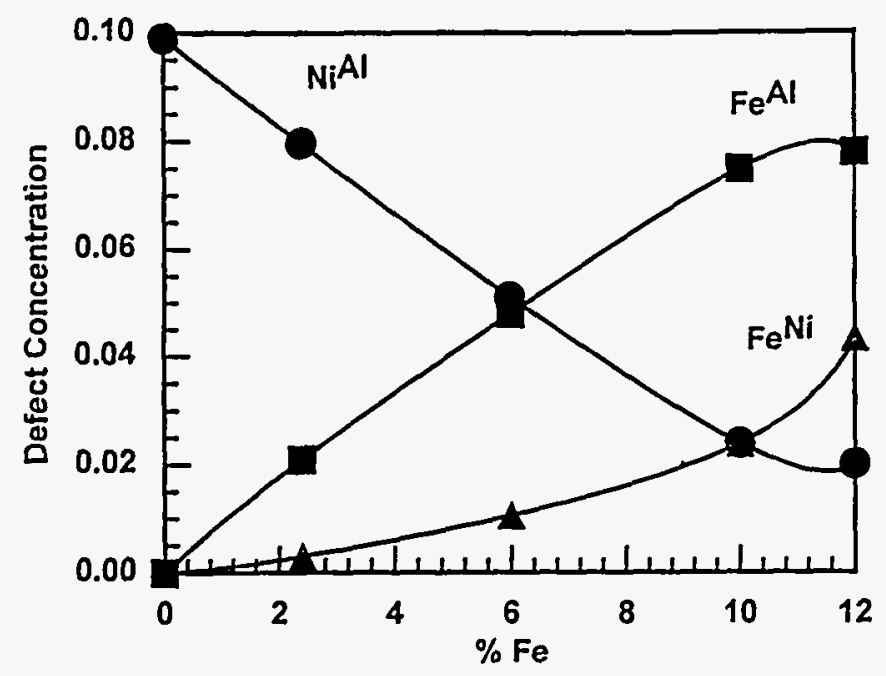

Figure 5: The concentrations of $\mathrm{Ni}^{\mathrm{Al}}, \mathrm{Fe}^{\mathrm{Al}}$, and $\mathrm{Fe}^{\mathrm{Ni}}$ defects vs. Fe concentration in the 40 at. \% Al alloys.

3.2.2 Fe added to Stoichiometric NiAl. We next consider the case where $\mathrm{Fe}$ is added to replace $\mathrm{Ni}$ in $\mathrm{Ni}-50 \mathrm{Al}$. Alloys were made from 0 to 10 at. $\% \mathrm{Fe}$, i.e. $\mathrm{Ni}_{50-x} \mathrm{Fe}_{x} \mathrm{Al}_{50}$ where $\mathrm{x}$ varies from 0 to 10 . The lattice parameters of the alloys as quenched from $1000^{\circ} \mathrm{C}$ are shown in Fig. 3 and are seen to decrease slightly as the concentration of $\mathrm{Fe}$ is increased. The bulk densities are listed in Table I. The vacancy concentrations are shown in Fig. 4 for samples quenched from $1000^{\circ} \mathrm{C}$. These are seen to monotonically increase from 0.003 to $0.013(0.3$ to $1.3 \%$ ) as the $\mathrm{Fe}$ concentration increases from 0 to 10 at. \%. A similar trend was observed in the samples quenched from $700^{\circ} \mathrm{C}$. The $\mathrm{Ni}$ and $\mathrm{Fe}$ anti-site concentrations are shown in Fig 6. These were calculated using the vacancy concentration measurements of the present study combined with the ALCHEMI data from Duncan (15). For "stoichiometric" alloys such as these, any anti-site type defects are thermal defects. From this data it can be seen that the anti-site defect concentrations are small (relative to the number of $\mathrm{Fe}^{\mathrm{Ni}}$ defects), and that those anti-site defects that are present are primarily $\mathrm{Fe}$ anti-sites. The number of $\mathrm{Fe}$ anti-sites is seen to increase slightly as the concentration of $\mathrm{Fe}$ is increased. However, the majority of the Fe is located on the Ni sublattice. The concentration of these $\mathrm{Fe}^{\mathrm{Ni}}$ defects are also shown in Fig 6 . Thermodynamic calculations by Kao et. al. yielded estimates qualitatively similar to the above results $(14,16)$.

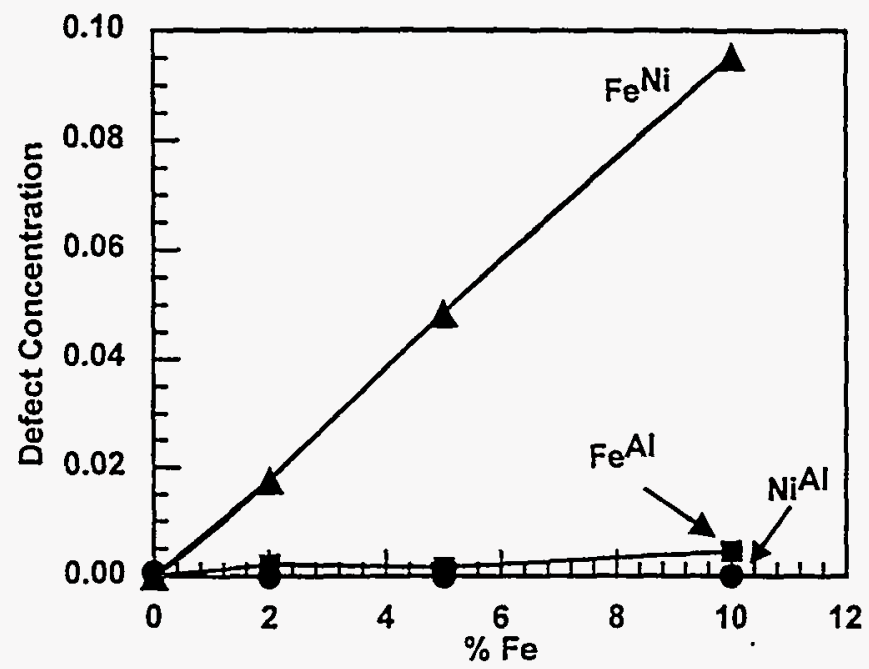

Figure 6: The concentrations of $\mathrm{Ni}^{\mathrm{Al}}, \mathrm{Fe}^{\mathrm{Al}}$, and $\mathrm{Fe} \mathrm{Ni}^{\mathrm{Ni}}$ defects vs. $\mathrm{Fe}$ concentration in the 50 at. \% Al alloys. This data is calculated using the present vacancy concentration combined with the ALCHEMI data of Duncan (15).

\subsection{Solid Solution Hardening in Fe doped NiAl}

As discussed in section 3.2, the addition of $\mathrm{Fe}$ to $\mathrm{NiAl}$ can significantly affect the numbers and types of point defects. Each of these defect types will have a unique hardening rate. In addition, as was seen in the preceding section, there is often more than one type of defect present in significant numbers. Based on information garnered from SSH in binary B2 compounds, much useful qualitative information can be found for the SSH in Fe-doped NiAl. However, if a quantitative method of examining the solid solution hardening behavior is desired when there is more than one defect type present. a method of adding the two effects must be considered. Numerous methods for adding the effects of multiple hardening sources have been suggested (a list of these has been compiled by Gypen and Deruyttere (17)). One of these proposed by Koppenaal and Kuhlmann-Wilsdorf (18) is the "mean square law". This assumption suggests that the square of the total increase in the shear yield stress is equal to the sum of the squares of the changes in the shear yield stress if the two defects were considered separately. In a computer simulation, Foreman and Makin (19) found this rule to be applicable to a wide range of situations. Furthermore, using theoretical arguments Gypen and Deruyttere (17) found the mean square law to be expected when the individual defect hardening follows a square root relationship. If the shear yield stress is assumed to be roughly proportional to the hardness, the mean square law can be extended to the change in hardness:

$$
\Delta H=\sqrt{\left(\gamma_{1} c_{1}^{1 / 2}\right)^{2}+\left(\gamma_{2} c_{2}{ }^{1 / 2}\right)^{2}+\ldots+\left(\gamma_{n} c_{n}^{1 / 2}\right)^{2}}
$$

where $H$ is the hardness, $\gamma_{x}$ and $c_{x}$ are the hardening rate and defect concentration of the defect of type $x$, and $n$ is the total number of different types of defects. The proportionality of the hardness to the yield stress is strictly valid only for perfectly plastic materials. 
Unfortunately, the brittle nature of many of these compounds often makes direct measurement of the yield stress difficult. In the following sections we will investigate the SSH behavior of Fe-doped $\mathrm{Ni}$-rich and stoichiometric $\mathrm{NiAl}$.

3.3.1 Fe added to Ni-rich NiAl. The hardness of the $\mathrm{Ni}_{60}$ ${ }_{x} \mathrm{Fe}_{x} \mathrm{Al}_{40}$ alloys is shown in Fig. 7. The hardness is seen to decrease with increasing Fe concentration. That is, Fe actually causes solid solution softening in Ni-rich NiAl. A rational explanation for this unusual observation can be offered after consideration of the effect of $\mathrm{Fe}$ on the point defect concentrations in these alloys. As discussed in section 3.2.1, the two major defects in these alloys are $\mathrm{Ni}$ and $\mathrm{Fe}$ anti-site defects. The former being replaced by the latter as the concentration of $\mathrm{Fe}$ is increased. The Goldschmidt radii of $\mathrm{Ni}, \mathrm{Fe}$, and $\mathrm{Al}$ are $1.24,1.27$, and 1.43 , respectively (20). A smaller $\mathrm{Ni}$ atom on the $\mathrm{Al}$ sublattice would obviously cause a contraction of the lattice and therefore be expected to harden the material. In a similar manner, an $\mathrm{Fe}$ atom on the $\mathrm{Al}$ sublattice would be expected to cause hardening. However, as the Fe atom is somewhat larger than the $\mathrm{Ni}$ atom, the $\mathrm{Fe}$ anti-site would be expected to be a less potent hardener than the $\mathrm{Ni}$ anti-site. Therefore, as $\mathrm{Fe}$ is added to $\mathrm{Ni}-40 \mathrm{Al}, \mathrm{Ni}$ anti-sites (potent hardeners) are being replaced by $\mathrm{Fe}$ anti-sites (less potent hardeners). The net result would be a decrease in hardness. This decrease is most likely responsible for the solid solution softening observed in Fig. 7.

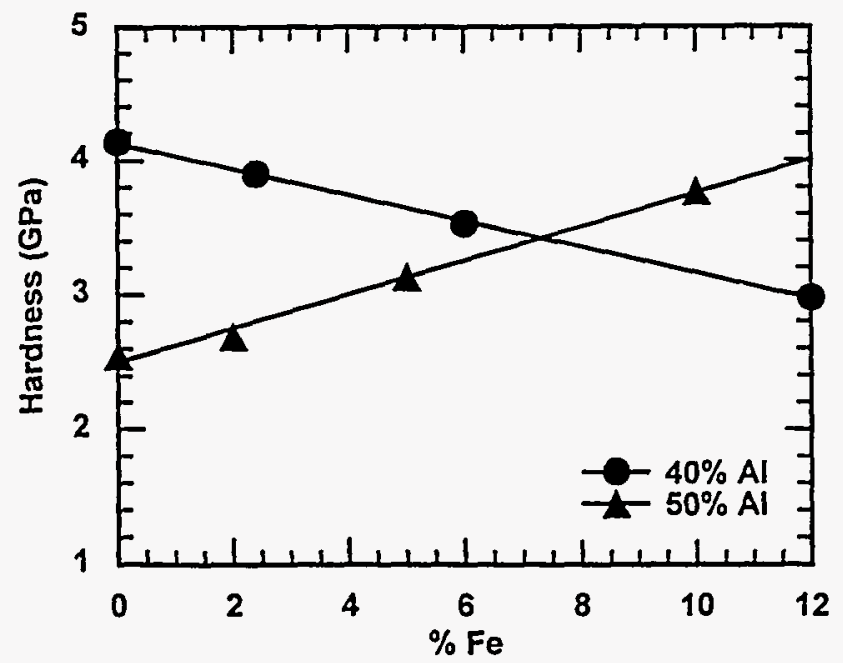

Figure 7: The hardness vs. Fe concentration.

Let us now consider whether the observed softening can be rationalized in a quantitative manner. From the study on binary $\mathrm{B} 2$ compounds the hardening rate of $\mathrm{Ni}$ anti-sites was around $\mathrm{G} / 12$ (4). However, the hardening rate of $\mathrm{Fe}$ anti-sites in $\mathrm{NiAl}$ is not directly measurable due to the presence of more than one type of defect. Nevertheless, it is possible to estimate this hardening rate by recalling that the hardening rate of anti-site type defects has been shown to correlate to the lattice dilation of the hardening defect (4). Thus, it becomes necessary to determine the lattice dilation of $\mathrm{Fe}$ anti-site defects. From lattice parameter data of binary $\mathrm{NiAl}$, the lattice dilation of $\mathrm{Ni}$ anti-sites was found to be -0.076 . The increase in the lattice parameter with increasing $\mathrm{Fe}$ concentration seen in Fig. 3 represents the sum of the effects of removing $\mathrm{Ni}$ anti-sites while adding $\mathrm{Fe}$ anti-sites. If it is assumed that lattice dilations add linearly when there is more than one type of defect present (a reasonable assumption considering most B2 compounds follow Vegard's law (9)), then the dilation of Fe anti-sites can be estimated from Fig. 3 to be -0.018 . Thus, the lattice dilation of $\mathrm{Fe}$ anti-sites is considerably less than that of $\mathrm{Ni}$ anti-sites. With this dilation, an estimate for the hardening rate of $\mathrm{Fe}$ anti-sites can be made from the observed relationships between hardening rates and lattice dilations in binary B2 compounds (4). A value in the range of $G / 25$ to $G / 600$ is found, making the $\mathrm{Fe}$ anti-site a relatively weak hardener.

Taking the hardening rate of $\mathrm{Ni}$ anti-sites (G/12) and the data of Fig. 7, Eq. 1 can be solved to estimate the hardening rate of $\mathrm{Fe}$ anti-sites. A value of $G / 35$ is found. This value lies well within the range estimated using the lattice dilation. The lattice dilations and hardening rates are summarized in Table II.

Table II The Lattice Dilations and Hardening Rates of Point Defects Important to this Study

\begin{tabular}{|c|c|c|c|c|}
\hline $\begin{array}{c}\text { Defect } \\
\text { Type }\end{array}$ & $\begin{array}{c}\text { Sub- } \\
\text { lattice }\end{array}$ & $\begin{array}{c}\text { Lattice } \\
\text { Dilation } \\
1 / \mathrm{a}(\mathrm{da} / \mathrm{dc})\end{array}$ & $\begin{array}{c}\text { Estimated } \\
\text { Hardening } \\
\text { Rate }^{\mathrm{a}} \\
\gamma(\mathrm{GPa})\end{array}$ & $\begin{array}{c}\text { Experimental } \\
\text { Hardening } \\
\text { Rate }^{\mathrm{a}} \\
\gamma(\mathrm{GPa})\end{array}$ \\
\hline vacancy & $\mathrm{Ni}$ & $-0.081(4)$ & - & $\mathrm{G} / 4.1(4)$ \\
\hline $\mathrm{Ni}$ anti-site & $\mathrm{Al}$ & $-0.076(4)$ & - & $\mathrm{G} / 12(4)$ \\
\hline $\mathrm{Fe}$ atom & $\mathrm{Ni}$ & $0.007(21)$ & $\begin{array}{c}\mathrm{G} / 40 \\
\text { to } 0^{\mathrm{b}}\end{array}$ & $\begin{array}{c}\text { less than } \\
\mathrm{G} / 60^{\mathrm{c}}\end{array}$ \\
\hline $\mathrm{Fe}$ atom & $\mathrm{Al}$ & -0.018 & $\begin{array}{c}\mathrm{G} / 25 \text { to } \\
\mathrm{G} / 600^{\circ}\end{array}$ & $\mathrm{G} / 35^{\mathrm{d}}$ \\
\hline
\end{tabular}

a The shear modulus, $\mathrm{G}$, of $\mathrm{NiAl}$ is $70 \mathrm{GPa}$ (22).

b These estimates are based on the lattice dilation and the data available for the relationship between the lattice dilations and hardening rates of anti- site defects in binary B2 compounds (4).

c From applying Eq. [1] to the hardening data for the addition of $\mathrm{Fe}$ to stoichiometric $\mathrm{NiAl}$.

d From applying Eq. [1] to the hardening data for the addition of Fe to Ni-rich NiAl.

3.3.2 Fe added to Stoichiometric NiAl. The hardness of the $\mathrm{Ni}_{50 \text { - }}$ ${ }_{x} \mathrm{Fe}_{\mathrm{x}} \mathrm{Al} \mathrm{l}_{50}$ alloys is shown in Fig. 7 to increase as the concentration of $\mathrm{Fe}$ is increased. From the discussion in section 3.2.2, we must consider three types of point defects in the stoichiometric alloys: $\mathrm{Fe}$ anti-sites, $\mathrm{Fe}$ on the $\mathrm{Ni}$ sublattice $\left(\mathrm{Fe}^{\mathrm{Ni}}\right.$ ), and vacancies. All of these defects increase in number as the concentration of $\mathrm{Fe}$ increases. The question arises as to how do these different defect types contribute to the observed hardening. The hardening rate of vacancies in $\mathrm{NiAl}$ is around $\mathrm{G} / 4.1$ (4), while the hardening rate of $\mathrm{Fe}$ anti-sites was found in the previous section to be around $\mathrm{G} / 35$. Thus, the only unknown hardening rate is that of the $\mathrm{Fe}^{\mathrm{Ni}}$ defects. The lattice dilation of these defects has been estimated to be 0.007 using lattice parameter data of $\mathrm{Al}$-rich $\mathrm{NiAl}$ (21). Following the relationship between hardening rates and lattice dilations in binary B2 compounds (4), a hardening rate of $G / 40$ to 0 can be estimated from this dilation. Solving Eq. [1] using the hardness data in Fig. 7, a hardening rate for $\mathrm{Fe}^{\mathrm{Ni}}$ defects of less than $\mathrm{G} / 60$ is calculated. This is well within the range estimated above. Consideration of the terms in Eq. [1] for this case reveals that the potent hardening rate of vacancies is responsible for making the vacancy term the dominant term in the equation. In effect, the observed hardening can be attributed solely to the increasing vacancy concentration. To 
illustrate this point consider Fig. 8 where the hardness of the stoichiometric alloys is plotted against the square root of the vacancy concentration. The data is sein to fall along a line. The slope of this line is $\mathrm{G} / 4.1$, the sam: hardening rate found for vacancies in binary $\mathrm{NiAl}$ (4). The strong role vacancies play in hardening these stoichiometric alloys nas also been explored by Duncan (15).

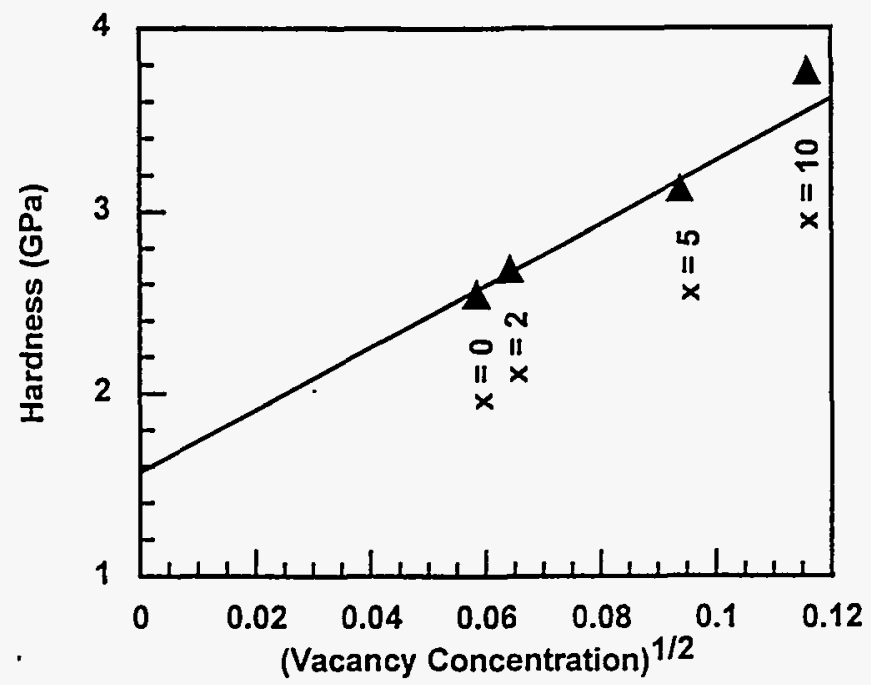

Figure 8: The hardness vs. the square root of the vacancy concentration in the $\mathrm{Ni}_{50-x} \mathrm{Fe}_{\mathrm{x}} \mathrm{Al}_{50}$ alloys.

\subsection{Conclusions}

The effects of $\mathrm{Fe}$ additions on the defect concentrations and the hardness of NiAl were investigated. Two compositional ranges were considered: Ni-rich and stoichiometric. It was found that there were significant differences in the hardening characteristics between the two regimes. An understanding of the site occupancy of the ternary Fe addition as well as the effect of this addition on the concentrations of other point defects. such as vacancies and $\mathrm{Ni}$ anti-site defects. was essential in rationalizing the observed hardening behaviors. To determine these defect concentrations, the vacancy concentration was experimentally determined on the Fe doped alloys. In addition. ALCHEMI was performed to determine the site occupancy of the $\mathrm{Fe}$ additions as well as the $\mathrm{Ni}$ anti-site concentrations. The lattice dilation of $\mathrm{Fe}$ defects on both the $\mathrm{Ni}$ and $\mathrm{Al}$ sublattices was estimated from lattice parameter data. Using the correlation between lattice dilation and hardening rates observed in binary B2 compounds (4), estimates were made of the hardening rates of these Fe defects.

Apparent solid solution softening by $\mathrm{Fe}$ was observed in the $\mathrm{Ni}$ rich alloys. This softening was attributed to the replacing of $\mathrm{Ni}$ anti-site defects (potent hardeners) with $\mathrm{Fe}$ anti-sites (less potent hardeners). The net result being a decrease in hardness with increasing $\mathrm{Fe}$ concentration. In the stoichiometric alloys a strong increase in the hardness was observed with increasing $\mathrm{Fe}$ concentration. This hardening was found to be stronger than would be expected from the Fe defects alone. This hardening was attributed to the increase in the vacancy concentration which occurs with the addition of Fe.

\section{Acknowledgments}

The authors would like to acknowledge Dr. I. M. Anderson for integral assistance in obtaining the ALCHEMI data and Dr. J. H. Schneibel and Dr. A. J. Duncan for helpful discussions. This research was sponsored by the Division of Material Sciences of the Basic Energy Sciences. U. S. Department of Energy under contract DE-AC-05-960R-22464 with Lockheed Martin Energy Research Corporation and subcontract SJ403-19 from Lockheed Martin Energy Research Corporation to the University of WisconsinMadison.

\section{$\underline{\text { References }}$}

1. J. Westbrook. J. Electochem. Soc. 54 (1956). 103.

2. P. Nagpal and 1. Baker, Metall. Trans., 21A (1990), 2281.

3. Y. A. Chang, L. M. Pike. C. T. Liu. A. R. Bilbrey, and D. S. Stone, Intermetallics, 1 (1993), 107.

4. L. M. Pike, Y. A. Chang, and C. T. Liu. Acta Metall., in press.

5. R. D. Noebe, R. R. Bowman. and M. V. Nathal. Inter. Mat. Reviews. 38 (1993), 193.

6. D. B. Miracle. Acta Metall. 41 (1993). 649.

7. R. Darolia. D. F. Lahrman. and R. D. Field. Scr. Metall. 26 (1992), 220.

8. I. Jung, M. Rudy, and G. Sauthoff. High Temperature Ordered Intermetallic Allovs II. vol. 81, ed. N. S. Stoloff, et al. (MRS Symp. Proc.. Pittsburgh, PA 1987) pp. 263-74.

9. Y. A. Chang and J. P. Neumann. Prog. Solid State Chem. 14 (1982). 221.

10. I. M. Anderson. A. J. Duncan. and J. Bentley, in High Temperature Ordered Intermetallic Allovs VI. vol. 364. ed. J. A. Horton, et al. (MRS Symp. Proc.. Pittsburgh. PA 1994) pp. 44354.

11. A. J. Bradley and A. Taylor. Proc. R. Soc. Lond.. A159 (1937), 56.

12. R. L. Fleischer. in The Strengthening of Metals. ed. by D. Peckner (Reinhold Publishing Corp.. New York, 1964). pp. 93-140.

13. I. M. Anderson. Acta Metall., in press.

14. C. R. Kao. L. M. Pike, S.-L. Chen and Y. A. Chang, Intermetallics. 2 (1994), 235.

15. A. J. Duncan. Ph.D. Thesis. University of Florida. 1995.

16. L. M. Pike, C. R. Kao. S. L. Chen. and Y. A. Change, in Design Fundamentals of High Temperature Composites. Intermetallics. and Metal-Ceramics Systems. ed. R. Y. Lin et. al. (TMS Publication, Warrendale. PA 1996) p. 171.

17. L. A. Gypen and A. Deruyttere, J. Mater. Res. 12 (1977), 1028.

18. T. J. Koppenaal and D. Kuhlmann-Wilsdorf. Appl. Phys. Letters, 4 (1964), 59.

19. A. J. E. Foreman and M. J. Makin, Phil. Mag., 22 (1966), 911.

20. F. Laves, in Theory of Allov Phases (ASM Publication. Cleveland, $\mathrm{OH}, 1956$ ).

21. L. M. Pike, unpublished data.

22. G. Simmons and H. Wang, Single Crystal Elastic Constants and Calculated Aggregate Properties: A Handbook, 2nd ed.. (MIT Press, Cambridge, MA, 1971). 